\title{
Commentary Septic shock resuscitation: what goals and how to achieve them?
}

\author{
Stephan M Jakob
}

Department of Intensive Care Medicine, University Hospital Bern (Inselspital) and University of Bern, CH-3010 Bern, Switzerland

Corresponding author: Stephan Jakob, Stephan.Jakob@insel.ch

Published: 18 May 2009

Critical Care 2009, 13:147 (doi:10.1186/cc7870)

This article is online at http://ccforum.com/content/13/3/147

(c) 2009 BioMed Central Ltd

See related research by Palizas et al., http://ccforum.com/content/13/2/R44

\begin{abstract}
The need to achieve adequate tissue oxygen delivery early in patients with septic shock is well established. However, it is less well recognized that tissue hypoperfusion can exist despite normalization of systemic hemodynamics. Efforts to resuscitate septic patients until adequate tissue perfusion has been achieved can potentially improve outcome. In a multicenter study, 130 patients with septic shock were resuscitated within 12 hours of diagnosis using a protocol including goals for mean arterial and pulmonary artery occluded pressures, urinary output, arterial $\mathrm{pH}$, and hemoglobin goals. They were then randomly assigned to further resuscitation with either a cardiac index $(\geq 31 /$ minute per $\mathrm{m}^{2}$ ) or a gastric mucosal $\mathrm{pH}(\geq 7.32)$ target. The intensive care unit length of stay and 28-day mortality did not differ between groups, but more patients in the cardiac index group were in the target range, both at baseline and after resuscitation, as compared with the gastric mucosal pH group. In contrast to cardiac index, gastric mucosal $\mathrm{pH}$ at baseline and at 24 and 48 hours predicted mortality. Whether other targets for the chosen variables, or different and - in particular - earlier resuscitation efforts would have favored one group cannot be concluded from the data provided.
\end{abstract}

The previous issue of Critical Care includes a report of a multicenter study in which cardiac index and gastric mucosal $\mathrm{pH}$ targets were compared during resuscitation of patients with septic shock [1]. Similar to all other hemodynamic variables with the exception of central venous oxygen saturation, the value of a cardiac index target in the resuscitation of patients in septic shock has not been established. In contrast, achievement of other goals in the treatment of septic patients (for instance, early and adequate antibiotic treatment) has been associated with improved outcomes. Because 'normal' systemic hemodynamics do not necessarily guarantee adequate tissue oxygen supply, monitoring organ perfusion or function may be more relevant. It has been shown that persistent microcirculatory alterations are associated with organ failure and mortality in patients with septic shock [2]. Gastric mucosal $\mathrm{pH}(\mathrm{pHi})$ is an interesting parameter that has been shown to predict outcome in many patient groups [3,4]. However, pHi-guided resuscitation has not improved survival rates. $\mathrm{pHi}$ is a composite variable that reflects not just adequacy of local perfusion but also systemic metabolic acid-base homeostasis and ventilation. The interaction of the components of $\mathrm{pHi}$ and their response to treatment may confound the interpretation and prognostic relevance of gastric mucosal acidosis.

In the study conducted by Palizas and coworkers [1], resuscitation to a pHi goal was not associated with better survival than resuscitation to a cardiac index target. Conceptually, there are four interpretations of these findings: the tested variables (cardiac index and $\mathrm{pHi}$ ) are not relevant to survival; the defined targets were not adequate; the targets were relevant but only in combination with the achievement of other goals; and finally, the efforts to achieve the goals were not adequate, and the goal therefore was not achieved.

\section{Were the tested parameters relevant for survival?}

Cardiac output determines tissue oxygen delivery and is certainly an important variable with respect to the resolution of septic shock. However, other variables contribute to tissue oxygen transport, and the demands may also vary. In that sense, as the authors state themselves [1], a goal representing a presumed adequate relationship between oxygen delivery and consumption (for example, mixed venous oxygen saturation) would have been preferable. Its strong association with mortality makes pHi an ideal target variable for improving outcomes.

\section{Were the defined targets adequate?}

In the study reported by Palizas and coworkers [1], the target cardiac index was achieved at baseline in nearly $90 \%$ of

$\mathrm{PCO}_{2}=$ carbon dioxide tension; $\mathrm{pHi}=$ gastric mucosal $\mathrm{pH}$. 
patients. Because the mortality was $30 \%$, it is clear that the target should have been higher, if increasing cardiac index is believed to be beneficial. In contrast, the incidence of low $\mathrm{pHi}$ was high. However, the variable is influenced by arterial carbon dioxide tension $\left(\mathrm{PCO}_{2}\right)$. It is a relatively common practice to increase minute ventilation in order to normalize arterial $\mathrm{pH}$ when bicarbonate is low. This will also increase $\mathrm{pHi}$ without improving mucosal perfusion [5]. Thus, the mucosal-arterial $\mathrm{PCO}_{2}$ gradient would have been a better choice. Whether a (normal) pHi of 7.32 can be achieved at all during the early phase of septic shock is questionable. The use of vasoconstrictors can decrease mesenteric perfusion, and metabolic effects of adrenaline (epinephrine) may increase $\mathrm{PCO}_{2}$ further.

\section{Were other important targets achieved?}

There is no information on how other aspects of septic shock treatment were addressed (antibiotics, source control, ventilator settings, and so on). This information would have enhanced ability to interpret the study findings.

\section{Were the measures to achieve the goals adequate and the goals achieved?}

Again, too few data are presented to answer this question. The authors indicate that crystalloids and colloids were given, but in their protocol only saline is listed. Although colloids can be harmful in sepsis [6], normal saline (or colloids in saline) can cause hyperchloremic metabolic acidosis and thereby decrease mucosal pHi. Adrenaline (epinephrine), noradrenaline (norepinephrine), dopamine, and dobutamine were used to improve blood pressure and flow. Although adrenaline can impair splanchnic perfusion in septic shock $[7,8]$, dobutamine appears to be able to reverse these changes, at least in part [9]. Dopamine can decrease splanchnic metabolic activity in patients with sepsis [10,11]. pHi was measured every 6 hours, and no data are given on the frequency of cardiac index assessments. Four daily assessments of the treatment's influence on the target variable may be too few, especially in view of the fact that splanchnic blood flow is highly variable in septic patients [12]. There was no increase in cardiac output or pHi over the 48-hour observation period.

It would have been interesting to see how the individual therapeutic interventions influenced the target variables. Without this information, the adequacy of the treatment cannot be determined. Nevertheless, the work by Palizas and coworkers [1] reminds us that mucosal acidosis persists in the majority of patients who ultimately will die after resuscitation from septic shock. Monitoring and treating tissue hypoperfusion therefore remains an option to improve outcome.

\section{Competing interests}

The Department of Intensive Care Medicine at Inselspital has or has had research contracts and/or collaboration contracts with Edwards Lifescience, GE Healthcare, Pulsion, Orion Pharma, Berna Biotech and B. Braun Medical.

\section{References}

1. Palizas F, Dubin A, Regueira T, Bruhn A, Knobel E, Lazzeri S, Baredes N, Hernández G: Gastric tonometry versus cardiac index as resuscitation goals in septic shock: a multicenter, randomized, controlled trial. Crit Care 2009, 13:R44.

2. Sakr Y, Dubois MJ, De Backer D, Creteur J, Vincent JL: Persistent microcirculatory alterations are associated with organ failure and death in patients with septic shock. Crit Care Med 2004, 32:1963-1964.

3. Theodoropoulos G, Lloyd LR, Cousins G, Pieper D: Intraoperative and early postoperative gastric intramucosal $\mathrm{pH}$ predicts morbidity and mortality after major abdominal surgery. $A m$ Surg 2001, 67:303-308.

4. Maynard N, Bihari D, Beale R, Smithies M, Baldock G, Mason R, McColl I: Assessment of splanchnic oxygenation by gastric tonometry in patients with acute circulatory failure. JAMA 1993, 270:1203-1210.

5. Jakob SM, Parviainen I, Ruokonen E, Kogan A, Takala J: Tonometry revisited: perfusion-related, metabolic, and respiratory components of gastric mucosal acidosis in acute cardiorespiratory failure. Shock 2008, 29:543-548.

6. Brunkhorst FM, Engel C, Bloos F, Meier-Hellmann A, Ragaller M, Weiler N, Moerer O, Gruendling M, Oppert M, Grond S, Olthoff D, Jaschinski U, John S, Rossaint R, Welte T, Schaefer M, Kern P, Kuhnt E, Kiehntopf M, Hartog C, Natanson C, Loeffler M, Reinhart K; German Competence Network Sepsis (SepNet): Intensive insulin therapy and pentastarch resuscitation in severe sepsis. N Engl J Med 2008, 358:125-139.

7. De Backer D, Creteur J, Silva E, Vincent JL: Effects of dopamine, norepinephrine, and epinephrine on the splanchnic circulation in septic shock: which is best? Crit Care Med 2003, 31: 1659-1667.

8. Levy B, Bollaert PE, Charpentier C, Nace L, Audibert G, Bauer P, Nabet $P$, Larcan A: Comparison of norepinephrine and dobutamine to epinephrine for hemodynamics, lactate metabolism, and gastric tonometric variables in septic shock: a prospective, randomized study. Intensive Care Med 1997, 23:282-287.

9. Levy B, Bollaert PE, Lucchelli JP, Sadoune LO, Nace L, Larcan A: Dobutamine improves the adequacy of gastric mucosal perfusion in epinephrine-treated septic shock. Crit Care Med 1997, 25:1649-1654.

10. Guérin JP, Levraut J, Samat-Long C, Leverve X, Grimaud D, Ichai C: Effects of dopamine and norepinephrine on systemic and hepatosplanchnic hemodynamics, oxygen exchange, and energy balance in vasoplegic septic patients. Shock 2005, 23: 18-24.

11. Jakob SM, Ruokonen E, Takala J: Effects of dopamine on systemic and regional blood flow and metabolism in septic and cardiac surgery patients. Shock 2002, 18:8-13.

12. Sakka SG, Reinhart K, Wegscheider K, Meier-Hellmann A: Variability of splanchnic blood flow in patients with sepsis. Intensive Care Med 2001, 27:1281-1287. 